\title{
ON SHAKEDOWN AND RATCHETTING OF CONFORMING FRICTIONAL SYSTEMS
}

\author{
M.Ciavarella \\ CEMEC-PoliBA - Centre of Excellence in Computational Mechanics \\ Politecnico di Bari, V.le Japigia 182, 70125 Bari, Italy
}

\begin{abstract}
Conforming contact is found on many important areas: materials with cracks, inclusions, layered structures, pinned geometries, etc. Coulomb friction is non-associative i.e. does not satisfy Drucker's postulates for stability in plasticity theory, and this does not permit to use the classical Melan and Koiter theorems for cyclic loading which however remain obvious necessary conditions. On the other hand, the Coulomb friction cone has a peculiarity, its linear self-similarity, and this permits few general results, quite different but also powerful. For example, we show that for conforming contact, the Bree interaction diagram is open and sectors-shaped, and therefore there is no lower and upper bounds as in plasticity, since there is linear dependence on a load parameter $\lambda$, and not a limit on $\lambda$. As there is dependence on initial conditions in general, the Bree diagram doesn't have the same profound meaning as in plasticity, since multiple steady states are possible. However, there is a complete scaling of the possible states (elastic shakedown, cyclic slip, ratchetting) with load factor $\lambda$, and hence a worst-scenario can be defined. However, in order to develop residual stresses (which generally will take many cycles of steady cyclic loading), the load cannot go to zero, at least for friction coefficient below the critical value for "wedging". More in general, there needs to be a "permanent stick region" in the steady state.

Almost conforming contacts, and in particular, in the case of initial interference, loose the independence on $\lambda$ at low $\lambda$ only, but "gain" greater possibilities to develop residual stresses. However, their study can be greatly simplified by developing a master curve approach to study the dependence on $\lambda$. The theorems can also be considered the extension to cyclic loadings of the Dundurs results for conforming contacts under monotonic loading, in which case the contact area doesn't vary in time and hence the problem is linear (from which the denomination "receding contacts"). However, here the problems remain fully non-linear, and the contact are not in general receding, nor there is a unique steady state, not even in the case of proportional loading. In the latter case it is neverthless possible to derive some special results.

Keywords. Shakedown, Receding contact, conforming contact, pinned connections, tolerances.
\end{abstract}




\section{INTRODUCTION}

Frictional contacts are everywhere in engineering and science since prehistorical times (see Dowson, 1998 ${ }^{1}$ ), and a large class is the conforming contact category (cracked materials with friction on crack faces, inclusions, layered structures, etc.).

For static (monotonic) loadings, a large literature exists in geotechnical engineering with methods like equilibrium methods stemming from the milestone paper by Coulomb (1776) who defined cohesion and friction ("cohésion" and "frottement" in the original) as "coercitive forces" to distinguish them from "active forces" such as gravity. Many later methods are remarkably close to the original Coulomb's method. Much later on, when the concept of stress was introduced, and plasticity theory developed (the "Yield Design" according to Salencon, 2002, par.6.2), , these methods were found close to "upper bound theorems" of plasticity theory, although the parallel is not exact. Also, friction and frictional materials are not associative, ie satisfying Drucker's stability postulate (Drucker, 1960). Hence, despite there are clear parallels between frictional slip and plastic deformation in elastic-plastic solids (both are dissipative mechanisms that depend on the history but not the rate of loading, and look similar in terms of a uniaxial force-displacement relationship), the analogies are not rigorous, as discussed perhaps first by Drucker (1954) who was able to define some bounds with limited use corresponding to (i) the rather artificial so-called Tresca (associative) friction, or (ii) to the infinite and (iii) zero friction cases.

Moving to the case of our interest, that of cyclic loadings, there is no equivalent of the early Literature on equilibrium methods for friction and frictional materials under cyclic loadings, whereas a huge literature has developed in associative plasticity. Starting from the pioneering works of Melan and Koiter, further extended to quite general material models (Halphen and Nguyen, 1975, see eg. three recent reviews by Maier 2001, Nguyen 2003, Polizzotto 2003), these theorems state conditions for certain loadings to give one of the possible responses:-

(1) (Elastic) shakedown, which corresponds to elastic behavious in the steady state after a certain transient. This is generally the most desirable long-term response since, hoping the amount of plastic deformation produced in the transient phase is sufficiently small, only High-Cycle Fatigue is produced in the steady state, not appearing as plastic deformations at the macroscopic scale. In the context of friction, this corresponds to no cyclic slip at the macroscopic scale, although perhaps to slip at asperity scale. As plastic deformations in materials, cyclic slip is also expected to be a form of damage for the surfaces, perhaps in the form of wear. This opens up the possibility that geometry changes need to be considered in some cases;

(2) Plastic shakedown (or Alternating plasticity collapse), in which the plastic strains are periodic like the stresses, giving low-cycle fatigue. In the case of friction, the macroscopic slip will give rise to frictional dissipation, damping, which may be beneficial in some cases. Here, in the much longer time scales typical of wear, we expect damage in the form of fretting wear;

\footnotetext{
${ }^{1}$ For an interesting and quick reference on the history of friction, see e.g. http://en.wikipedia.org/wiki/Guillaume_Amontons
} 
(3) Ratchetting (or incremental collapse), in which somewhere in the body the steady cycle has a nonvanishing plastic strain ratchet. Exhaustion of ductility rapidly leads to failure in plastic materials. In the case of friction, clearly there is no "failure" in this sense, but the fact that components may not be in the expected position may give rise to problems when this motion is not desired (see eg. Antoni et al. 2007). This problem in effect is known in many technical areas with perhaps different denominations. In mechanical industries of bushings it is known as "microreptation" or "cumulative microslip phenomenon" (Antoni et al., 2007), or simply frictional "slip" (Anscombe and Johnson 1974, and Chang et al 1983). This is often due to the nature of rolling contact loads, which may make the tyre or the bushing to creep circumferentially round the core of the wheel in the direction of the peripheral motion of the wheel. The same problem is experienced in creepage of a pavement or a road under rolling motions of vehicles ("subsurface slip" see eg Boulbibane et al 2005), or the ratchetting of long pipelines over their frictional supports (particularly, under thermal loading), a phenomenon recently of significant interest (Carr et al 2006a, 2006b, Bruton et al 2005).

The theorems show that essentially the steady-state response to cyclic loading is of a unique type (elastic shakedown, or cyclic plasticity, or ratchetting), independently on the initial conditions which only affect the residual constant stresses in the steady state, and give ways to recognize the limits. Melan's theorem in particular, is extremely simple and makes use only of equilibrium and the yield stress conditions. In other words, using terminology of frictional contact, such a theorem might be enunciated as: "If a set of time-independent tangential displacements at the interface can be identified such that the corresponding residual stresses when superposed on the time-varying stresses due to the applied loads cause the interface tractions to satisfy the conditions for frictional stick throughout the contact area at all times, then the system will eventually shake down to a state involving no slip, though not necessarily to the state so identified."

More in general, let us consider the usual case of cyclic load composed of a mean load and cyclic load component

$$
\mathbf{P}(t)=\alpha \mathbf{P}_{m}+\beta \mathbf{P}_{c}(t)
$$

This for a classical elasto-plastic material and structure, the "yield stress" will correspond to limit values of $\alpha, \beta$ for which there is plastic collapse, which define a bounded region in the $\alpha, \beta$ space, within which we can plot useful sub-regions (the Bree-diagram, see Fig.1), corresponding each to a well defined cyclic steady state behaviour, independent on the initial conditions when the steady cyclic loads are applied. Hence, the Bree interaction diagram turns out very useful for design purposes.

From Fig. 1, it can be easily remarked that the elastic shakedown boundary with the plastic shakedown one is a horizontal line, i.e. changing the mean load alone, seems not to cause the system to move from elastic shakedown to plastic shakedown. Indeed, as shown by Polizzotto (1993a, 1994a,b), any cyclic load which exceeds the ratchet limit, can always be transformed into one not exceeding this limit by simply superposing a permanent (mechanical) mean load, and generally at low levels of cyclic loads, we move into elastic shakedown as clear from the point $P_{1}$ in Fig.1, whereas at higher cyclic loads, to alternating plasticity as for point $P_{2}$. 


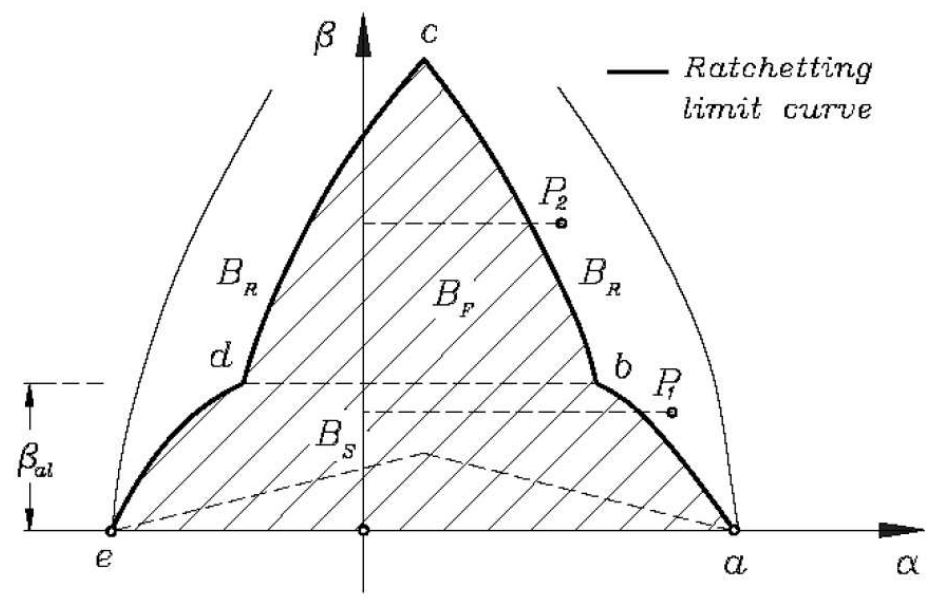

Fig. 1. The Bree diagram (from Polizzotto, 2003). $B_{s}$ is the elastic shakedown region, $B_{F}$ is the alternating plasticity, $B_{R}$ is the ratchetting region

In the original and still common formulation, the problem is written in terms of a single scalar $\lambda$, when for a given $\gamma$ we increase the entire loading cycle as

$$
\mathbf{P}(t)=\lambda\left[\mathbf{P}_{m}+\gamma \mathbf{P}_{c}(t)\right]
$$

This also corresponds obviously to exploring the Bree diagram for inclined lines from the origin where $\lambda=\alpha$ and $\gamma=\frac{\beta}{\alpha}$. This type of notation is also responsible for the terminology "lower bound" theorem, for Melan's theorem, and "upper bound" theorem, for Koiter's. In fact, in the original Melan's formulation, there is no distinction of mean load and cyclic loads and a single scalar $\lambda$ increases the loads. Therefore, one can apply Melan's theorem to predict a lower bound for $\lambda$ such that, for $\lambda<\lambda_{L B}$, there will be shakedown. Further, by applying Koiter's theorem, one can find an upper bound for $\lambda$ i.e that for $\lambda>\lambda_{U B}$, there will be ratchetting. By finding better estimates for Melan and Koiter theorems, one could close the gap, and if the two bounds do not coincide, there is a region of alternating plasticity in between.

The notation "lower bound" and "upper bound" could also be used for the multiplier of the cyclic part of the loading, as Fig.1 seems to indicate that increasing the cyclic loads, one cannot move from shakedown to ratchetting, and back to shakedown (there is no proof that we are aware of this). Certainly not the same can be done by fixing the cyclic loading part and changing the mean part only, since from Fig.1 it is evident that we could move from ratchetting to cyclic plasticity back to ratchetting again.

\subsection{Frictional contacts}

One first clear element show that the picture is completely different in frictional systems: while normally, a plasticity law defines as a material property a yield strength, of dimension of a stress $\left[F / L^{2}\right]$, the Coulomb friction law doesn't introduce any such quantity, Coulomb's cone based on a purely geometrical quantity (the cone angle). The limit in shear is defined by the local pressure, which in turn is intrinsic in the solution of 
the problem. Assuming constant pressure, the classical perspective is recovered, as well as the possibility to apply the theorems. Indeed, some authors have used plasticity theorems, assuming Tresca friction, i.e. that normal pressure is prescribed by equilibrium, or dictated as a boundary condition datum (Antoni et al. 2007, Churchman et al, 2006). This leads to the cyclic loading equivalent of the Tresca friction theorems developed by Drucker (1954), but the problem's formulation is very remote from the realistic case as Drucker already remarked, especially at a continuum level rather than with simple concentrated block models. Indeed, in contact problems, the pressure cannot be controlled locally, and goes to zero towards the end of the contact area because of asymptotics prescribed by elasticity, indicating that these regions are very prone to microslip - see eg. the classical Cattaneo-Mindlin-Dereciewicz problem for the Hertz geometry, (Johnson, 1985), for which it is clear that microslip occurs in the general case, as only for special proportional oblique loading there can be absence of slip, and in general the tendency to shakedown is observed as reduction of the slip areas in the steady state in cases with nonzero mean load (Dini and Hills, 2004). This is "unfortunate", since the steady cycle of a cyclically loaded associative plastic structure can be directly (i.e. without the use of step-by-step analyses) determined, at least in principle, by means of a particular equation set, for example by Polizzotto (1993a,b, 1994b) for elastic-perfectly plastic materials, by Halphen (1979) for elasticplastic internal-variable material models, etc.

Notice that the necessary part of Melan's theorem (1936) remains valid (Maier, 1969), ie for a given cyclic load, if there is no a feasible set of residual stresses which permit to avoid slip, the system cannot shakedown. For the sufficient part, it was proved recently (Klarbring et al 2007) that the conditions for an elastic frictional contact problem (in a discrete, e.g. finite element) formulation are rather strong and restrictive: contact is to be 'complete' - i.e. the contact area should remain constant throughout the loading cycle, and the geometry should be uncoupled, so that pressure can change only independently on frictional (tangential) displacement ${ }^{2}$. In all other conditions, it was proved that Melan doesn't hold and generally the possible final states for a given cyclic load can be both elastic shakedown and cyclic slip (actually, ratchetting cannot be ruled out in principle even below Melan's associative limit) depending on initial conditions, particularly for 3D problems, where this is true already for a single node system. Under these conditions, the step-by-step analysis only can tell the final state of the system. Hence, frictional systems in these respect are therefore more complex than associative elastic-plastic and elasticviscoplastic materials and structures, which subjected to mechanical and/or kinematical cyclic (i.e. periodic) loads, exhibits a long-term stabilized (or steady state) response, for which the initial conditions only define some relatively non relevant features of the steady state (the residual stresses).

However, a peculiar property of the problem is the (linear) self-similarity of the Coulomb law, for which we have perfectly linear equalities and inequalities ruling the contact problem, which give rise to special properties in the case of conforming contacts, which are those for which the contact conditions are homogeneous. While Coulomb friction

\footnotetext{
${ }^{2}$ Alternatively, an extremely special geometrical condition should be met.
} 
is more complex in the sense that it introduces non-associativity, it is also simpler than most plasticity laws, because it is self-similar.

\section{CONFORMING CONTACT PROBLEMS}

Conforming contacts are those for which there is no initial gap in the unstressed case (nor initial stresses), and are found in a wide range of applications in science and engineering (see Fig.5 for some examples). An actual application of fundamental importance is the case of cracks (not represented, and not discussed here for brevity), see Carpinteri and Scavia (1993).

Contact of fractured surfaces, layered structures, inclusions in metals, composite materials including contact between fibers and matrices, or between layers of different material properties, are all falling in this category. These contacts all look conforming at the scale of engineering interest where the Coulomb law is defined (ie neglecting the inevitable roughness at the interface which is strongly responsible for the Coulomb law behaviour).

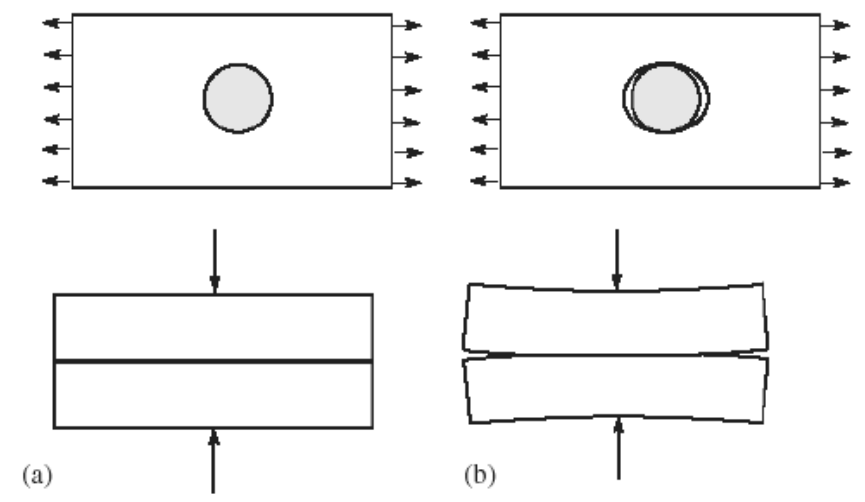

Fig. 2. Examples of contacts with no initial gaps in science and engineering. (a) unloaded (b) loaded

In engineering, limiting the attention to pinned connection alone, the literature is replete with studies because of the extensive use of pin joints in civil, mechanical and aerospace structures and some design codes also provide useful design guides. Then, we have the case of elastic inclusions, of composite materials, etc (useful but by far incomplete list is in Ciavarella et al., 2006). Under monotonic loading, these problems show the "receding contact" characteristic as proved by Dundurs and Stippes (1970) and Dundurs (1975), ie. if there are no initial stresses, the extent of the contact area $\Gamma_{C}$ under load is included within the contact area $\Gamma_{0}$ at zero load - i.e. $\Gamma_{C} \in \Gamma_{0}$. The concept is further explored in Ciavarella et al. (2006) to the case of friction, and to situations in which the initial contact area is not complete, proving that in the case of initial interference, the contact area decreases towards the limit described as regressive contact, whilst the opposite case where the contact area grows towards the limit will be described as progressive 
contact. It was proved that the receding contact is the limiting state in any case. The defining characteristic of a receding contact is that the contact area decreases as soon as the load is applied and then remains constant with increasing load, during which the stresses and displacements are everywhere proportional to the applied load. These properties are easily established by writing the governing equations and the boundary conditions for the problem, as done in Ciavarella et al. (2006).

Recently $^{3}$, Ahn \& Barber (2008) have extended these type of reasoning to proportional but non-monotonic loadings, and we shall return to this special case in a later paragraph. We shall viceversa deal with the general case of cyclic loading. In view of the interest to know if a limit cycle is reached in these system, and to characterize this state, in the most general possible case, we shall try to extend the Dundurs type of approach in the most general possible way (that we can imagine). Notice immediately that Dundurs used the monotonicity of the loading to prove a constant contact area, whereas here we don't expect the contact area to be constant except perhaps in the very first cycle of loading, if we start from an unstressed condition. When the load varies in time in a fairly general manner, the area will change in time in a correspondingly rich manner, depending on both geometry, and evolution of residual locked-in displacements, in turn coupled to the pressure. Therefore, nothing a priori can be said about the evolution of the slip displacements, except we shall expect an asymptotic steady state ${ }^{4}$, and the interest here will be to prove how all this state of affairs is mapped into the corresponding case when the loads are all multiplied by a scalar $\lambda$.

The stresses $\sigma$ and displacements $\mathbf{u}$ are required to satisfy the governing equations of elasticity which are here omitted in the interest of brevity. Surface tractions $\tau$ are defined as

$$
\tau_{i}=\sigma_{i j} \mathbf{n}_{j}
$$

where $\mathbf{n}$ is the outward normal unit vector. The normal traction (pressure) is then $\tau_{n}=\tau . \mathbf{n}$ and we define the shear traction

$$
\tau_{s}=\tau-\tau_{n} \mathbf{n}
$$

Notice that in three dimensional problems, $\tau_{s}$ is a vector in the tangent plane to the local surface.

Since we consider a quasi-static problem, in the instantaneous contact region $\Gamma_{C}$, $\mathbf{n}^{(1)}=-\mathbf{n}^{(2)}$ and when we have Coulomb friction $\Gamma_{C}$ must be divided into a slip region

\footnotetext{
${ }^{3}$ In fact, this paper was received by the author from Prof. Barber by coincidence when the present paper was nearly finished, providing however additional useful details over a particular case, and an useful example solved numerically.

${ }^{4}$ We expect qualitatively that the convergence to the steady state in frictional problems depends on the "memory" of the system. For example, as we shall see, if there is no possibility of developing residual stress states, ie no memory, convergence will be istantaneous, whereas it will occur in few cycles or even many cycles of loading, if there is strong memory in a cyclic stick region.
} 
$\Gamma_{S}$ and a stick region $\Gamma_{C}-\Gamma_{S}$. In $\Gamma_{S}$, the slip region

$$
\begin{aligned}
\left(\mathbf{u}^{(2)}-\mathbf{u}^{(1)}\right) \cdot \mathbf{n}^{(1)} & =0 ; \quad \tau_{n}^{(1)}=\tau_{n}^{(2)} \leq 0 \\
\tau_{s}^{(1)} & =-\tau_{s}^{(2)}=-\frac{f\left(\dot{\mathbf{u}}^{(2)}-\dot{\mathbf{u}}^{(1)}\right) \tau_{n}^{(1)}}{\left|\dot{\mathbf{u}}^{(2)}-\dot{\mathbf{u}}^{(1)}\right|}
\end{aligned}
$$

and in $\Gamma_{C}-\Gamma_{S}$, the stick region

$$
\begin{aligned}
\left(\mathbf{u}^{(2)}-\mathbf{u}^{(1)}\right) \cdot \mathbf{n}^{(1)} & =0 ; \quad \tau_{n}^{(1)}=\tau_{n}^{(2)} \leq 0 \\
\dot{\mathbf{u}}^{(2)}-\dot{\mathbf{u}}^{(1)} & =0 ; \quad \tau_{s}^{(1)}=-\tau_{s}^{(2)} ; \quad\left|\tau_{s}^{(1)}\right|<-f \tau_{n}^{(1)},
\end{aligned}
$$

where the dot denotes differentiation with respect to time $t$, and the superscripts denote the two contacting bodies. In the region $\Gamma_{0}-\Gamma_{C}$ that separates during loading

$$
\left(\mathbf{u}^{(2)}-\mathbf{u}^{(1)}\right) \cdot \mathbf{n}^{(1)} \geq 0 ; \quad \tau_{s}^{(1)}=\tau_{s}^{(2)}=0 ; \quad \tau_{n}^{(1)}=\tau_{n}^{(2)}=0 .
$$

The inequalities in $(5,7)$ state respectively that the normal contact traction must be compressive and the gap between the separated surfaces must be positive. The remainder of the boundaries of the bodies comprise a region $\Gamma_{D}$ where

$$
\mathbf{u}=\mathbf{U}(t)
$$

and a region $\Gamma_{N}$ where

$$
\tau=\mathbf{T}(t)
$$

and $\mathbf{U}, \mathbf{T}$ are prescribed displacements and tractions respectively ${ }^{5}$, function of time.

Theorem: Suppose the solution $\sigma, \mathbf{u}$ of this problem is known for some particular $\mathbf{U}, \mathbf{T}$. Thus, the solution obtained for the same contact area (independent of $\lambda$ ) which varies linearly with $\lambda$ satisfies all the conditions of the problem and hence defines also a solution.

Proof: the governing equations and the contact boundary conditions (5-9) are homogeneous, the solution $\lambda \sigma, \lambda \mathbf{u}$ will also satisfy these equations and correspond to proportional loading $\lambda \mathbf{U}, \lambda \mathbf{T}$, where $\lambda$ is a scalar multiplier. Furthermore, the inequalities in $(5,7)$ will also be satisfied by $\lambda \sigma, \lambda \mathbf{u}$ as long as $\lambda>0$.

Notice that this doesn't preclude the contact area to vary in a quite general manner in time, in particular it can change completely position if the loading is such as to change completely directions during the cycle.

In view of the fact that there is no general uniqueness proof, except for the frictionless case (Fichera, 1972) of for sufficiently low coefficients (Andersson, 1999), Andersson and Klarbring 2001), the solution may not be unique for the rate problem. Clearly, if the solution of the transient problem is non-unique, a fortiori the steady state solution may not be of unique type. The rate problem is related to the critical coefficient for uniqueness, whereas the type of steady state, it is connected to the development of residual stresses, value.

${ }^{5}$ Usually, we consider zero prescribed displacements, so that only prescribed traction is a finite 
and hence of the multiplicity of the solutions for the integrated problem for a given load type and system, including friction coefficient.

Both the rate and the integrated problems are unique for zero friction, and the latter case is obvious from a physical point of view, because with zero friction, there cannot be any residual shear stress. Notice that even the frictionless problem for conforming contact is fully non-linear, except in the case of proportional loading, since in general the contact area will vary with load. Hence, for finite friction, for any given load, we can imagine that there can be various solutions differing by a self-equilibrated field of shear tractions (since the global equilibrium has to be satisfied for the same applied loads). Now, it is easy to imagine that with higher and higher friction, many more possibilities exist, for the integrated problem, and perhaps even for the rate-problem, above the critical coefficient for uniqueness. In the limit, for infinite friction, any shear stress can be sustained by any non-zero pressure ${ }^{6}$. The problem for finite load is clearly the generalization of the so-called "wedging" problem (Barber and Hild, 2006). In the wedging problem, we look to the case of zero applied loads. This leads to define a critical value for friction, $f_{\text {wedg }}$, above which there are multiple solutions of the integrated problem even at zero load. In the case of a finite load, intuitive reasoning suggests the possibility to develop "protective" residual stresses during cyclic loading, the process leading possibly to shakedown, is open for any non-zero value of $f$ (look for example at the simple Klarbring single node system later). Wedging is more difficult because for zero loads, generally the pressure tends to be strictly zero, unless the coupling is strong enough to get any non-zero level of pressure able to sustain shear tractions.

However, starting from any one of the multiple solutions for the integrated problem at a given load level, the obtained response will be also valid as a response for the same problem when the loads are increased by $\lambda$, once all the terms of the solution are scaled accordingly. This includes also the case that friction is higher than the critical value for uniqueness or the rate problem, $f_{c r}$. In fact, a quasi-static regularization of the $2 \mathrm{D}$ problem for $f>f_{c r}$ can be defined (Cho and Barber, 1998), which permits to find the solution, which physically corresponds to the solution of the more general dynamic problem in the limit of some infinitesimal mass. The solution found with this algorithm, will be able to discern which of the various apparently instantaneously valid states, is to be preferred. And, again, the case with larger loads multiplied by $\lambda$, needs not to be studied again.

The situation in $3 \mathrm{D}$ is more complicated in the case of $f>f_{c r}$ from the physical point of view. In fact, adding the mass to possibly regularize the supercritical case shows that indeed the real dynamic problem is different from the quasi-static approximation already for $f<f_{c r}$. Indeed, dynamic instabilities arise for some types of loading, leading to stick-slip or other complex behaviour (Cho and Barber, 1999). Some of these effects will

\footnotetext{
${ }^{6}$ The parameter "friction coefficient", is a non-linearity parameter, although not the only one as we have seen that the frictionless case also is non-linear. Hence, it is entirely expected, particularly in the full dynamic case, that special values of friction coefficient exist qualitatively changes and bifurcations, perhaps leading also to period-doubling or even chaos. Some indication of this is for example the discussion of the 3D Klarbring model later, where we see that dynamic instabilities exist and one may perhaps imagine that a simple steady state will not be reached.
} 
be clearer in the example section when we discuss the behaviour of the very basic models of friction devised by Klarbing (1990), to study uniqueness and stability of Coulomb friction. Summarizing:-

- if both the transient and the cyclic parts of the loading are scaled by $\lambda$, then the problems at different $\lambda$ will look exactly identical, one cannot make any distinction between them.

- If, as more interesting, we cannot guarantee what happens in the transient part of the loading, then the long term cyclic response to the steady state loading, will depend in general on the initial conditions, and this is exactly in the nature of the non-associative shakedown problem. The associative case is the most efficient in these respect, since the system leads to shakedown, if there is one. The non associativity of Coulomb friction means, viceversa, that sometimes this limit cannot be found by the system. What is to be remarked however is that the entire set of scenarios will be scaled with $\lambda$. In other words, for every given set of possible initial conditions, the steady state will have accordingly a set of solutions. The problem with different $\lambda$ will also have the same set of solutions. There is no point to study problems at different $\lambda$

- The Bree diagram (intended as response to cyclic loading) will therefore have to be a system of sectors, since increasing $\lambda$ corresponds to navigate into the diagram over inclined lines. If we plot quantities as coutour maps in the Bree diagrams, they will be linear with $\lambda$. However, changing the line slope $\gamma=\frac{\beta}{\alpha}$, the relationships are not necessarily linear, and actually generally not linear. Hence, the functions will be of the self-similar type

$$
F_{i}(\alpha, \beta)=\lambda G_{i}(\gamma)
$$

where the pedix "i" is introduced in view of the possible multiplicity of regimes.

- If we take the worst scenario for a given quantity (cyclic slip, energy dissipation, etc.), for example, then the worst scenario for the same quantity in the problem with larger $\lambda$ will be exactly increased by the factor $\lambda$. In the case of the elastic shakedown subset of solutions, the residual stresses will be scaled. In the case of ratchetting, the ratchet rate. In functional form, one finds worst case scenario (wcs) ones

$$
F_{w c s}(\alpha, \beta)=\lambda G_{w c s}(\gamma)
$$

There are some cases when it is possible to have regions of single behaviour in a given wedge, i.e. independent on the initial conditions. We shall see this in the examples.

Notice that this uncertainty is not however completely general, as for example in the regions where the necessary part of Melan doesn't hold, we know that there cannot be shakedown for a given $\lambda$, and this means that there will be no shakedown for any $\lambda$. Therefore, we can already split the Bree diagram in sector regions of NO-SD, and complementary regions of possible-SD. The latter is given by the standard Melan's theorem, and includes (or coincides) the area where elastic shakedown occurs (if any).

Naturally, in order to have "locked-in" tangential displacements, we need during the cycle a "permanent stick zone", and actually even before that, a "permanent contact area" 
i.e. a region where non-zero pressure need to be present during the entire cycle. Hence, we need to have $\mathbf{P}(t) \neq 0$ at least for the most common case where there is no wedging,

for $f<f_{\text {wedg }}$ and $\mathbf{P}_{m}+\gamma \mathbf{P}_{c}(t) \neq 0 \Longrightarrow$ possible development of residual stresses

where $f_{\text {wedg }}$ is the critical coefficient for wedging see Barber and Hild (2006).

In the opposite case, i.e. if there is a $t_{1}$ such that

for $f<f_{\text {wedg }}$ and $\mathbf{P}_{m}+\gamma \mathbf{P}_{c}\left(t_{1}\right)=0 \Longrightarrow$ no development of residual stresses

there is no history dependence and the limit cycle is the same as the first cycle, although always of the same (non-linear) type. Naturally, for a case of high friction, ie for $f<f_{\text {wedg }}$ , then the load can also pass through the zero, and indeed one or more of the wedging states will be recovered there during the evolution of the process.

These above are only necessary conditions to have a "permanent contact area", but they are by far not sufficient. Indeed, if the loading is such that the contact areas don't overlap during the cycle, or even just the stick areas don't overlap, then there is no chance to develop residual stresses. It is not possible to write these conditions in explicit terms, but clearly more "non-proportionality" seems to suggest less chance to have permanent stick areas. Another interesting case when we can rule out permanent stick zones is the case of travelling load, which we shall deal with in the Example section.

\subsection{Proportional loading}

In the special case when we can write the load in terms of a constant vector $\mathbf{P}$, and the time dependence is contained in a separate function, we have "proportional loading", i.e.

$$
\mathbf{P}(t)=\lambda g(t) \mathbf{P}
$$

In this case, the analysis in the previous paragraph applies with a special meaning. In fact, we can introduce the time variation in the linear term and repeat the reasoning for constant $\lambda$ while the entire $g(t)$ varies. However, one problem with this is that now there is possibility of inversion of sign on the time-derivative of $f(t)$. Indeed, if we substitute this expression $\lambda g(t) \mathbf{P}$ in the solution obtained for $\mathbf{P}$, into the governing equations and inequalities, the factor $\lambda g(t)$ will cancel in all except in $5_{I I}$, which reduces to

$$
\tau_{s}^{(1)}=-\tau_{s}^{(2)}=-\frac{g^{\prime}(t)}{\left|g^{\prime}(t)\right|} \frac{f\left(\dot{\mathbf{u}}^{(2)}-\dot{\mathbf{u}}^{(1)}\right) \tau_{n}^{(1)}}{\left|\dot{\mathbf{u}}^{(2)}-\dot{\mathbf{u}}^{(1)}\right|}
$$

Hence, it follows that the Theorem doesn't hold more in general, as $g^{\prime}(t)$ changes in time and cannot be included in the factor $\lambda$. This means that the contact, the stick and the slip areas will not remain constant during the cycle. Therefore there is not a big difference with the general case, as even every loading cycle will not satisfy the original property of the loading phase with no "locked-in" tangential displacements (i.e. the sudden jump of the contact, stick, slip areas to the final value independent on the load). Naturally, in order to have "locked-in" tangential displacements, we need during the cycle a "permanent stick zone", and actually even before that, a "permanent contact area" i.e. a region where non-zero pressure need to be present during the entire cycle. Hence, since for zero loads 
the pressure will shrink to zero unless there is wedging ie for $f<f_{\text {wedg }}$ where $f_{\text {wedg }}$ is the critical coefficient for wedging see Barber and Hild (2006), the necessary condition to have development of residual stresses is a positive minimum value ratios in the function $g(t)$,

$$
\text { for } f<f_{\text {wedg }}, g_{\min }>0 \Longrightarrow \text { possible development of residual stresses }
$$

whereas in case

$$
\text { for } f<f_{\text {wedg }} \text { and } g_{\min } \leqslant 0 \Longrightarrow \text { no development of residual stresses }
$$

there is no history dependence and the limit cycle is the same as the first cycle so that the loading phase will always be linear, and the unloading always of the same (non-linear) type.

In the example presented by Ahn and Barber (2008), see fig. 6, the loading is such that $g_{\min }>0$, and hence there is some development of residual stresses tending to reduce the extent of slip zones and energy dissipation.

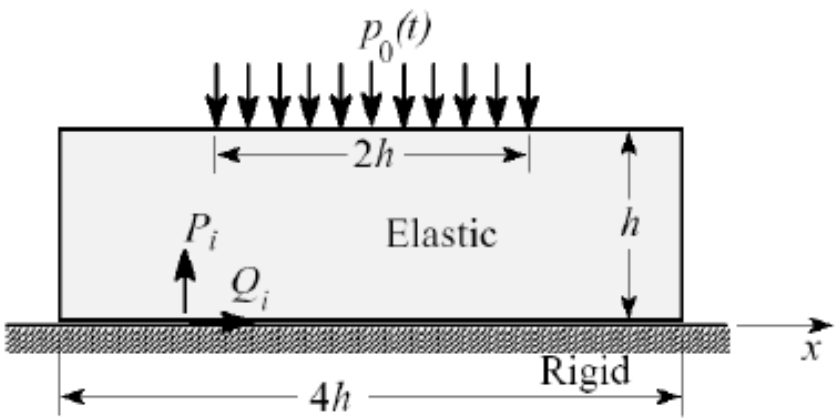

Fig. 3. The example conforming contact with proportional loading studied by Ahn and Barber (2008)

The problem is coupled as the pressures have an effect of shear tractions. The results on the first loading is shown in fig. 7 in the left, and after first unloading on the right. The first loading phase (starting from no locked in tractions since there is zero load) is entirely linear, with both pressures and shear tractions growing linearly with load, the problem becomes non-linear upon unloading, with the position of the regions and the both traction distributions varying non-linearly with load. A complex pattern of slip zones appears, but the central stick zone (which was reduced during unloading), slowly grows asymptotically tending to a limit value. The problem shows the same features of the classical MindlinDereciewicz with mean load, as shown by Dini and Hills (2004), i.e. a reduction of the slip regions in the steady state, and consequently also of the energy dissipation.

It may be speculated at this point, that proportional loading is much more likely to give rise to "beneficial" residual stresses (hardly complete shakedown however because of the contact edges zero pressure), if only because the contact area doesn't change as much as it could change in the general case. For example, in the case of a non-proportional loading where the contact areas during the cycle don't overlap at all, it is sure that there cannot be any residual stress developed, and hence no memory, no dependence on initial 

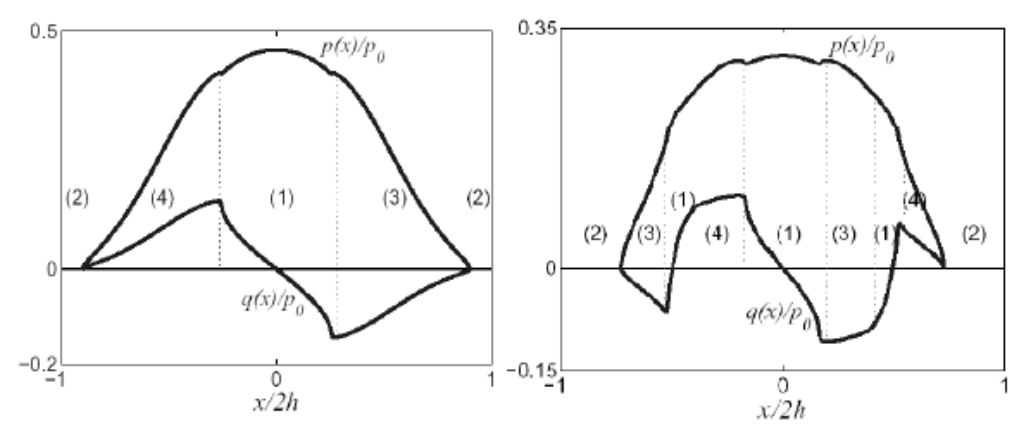

Fig. 4. The results for traction distributions in the problem of Ahn and Barber (2008): first loading in the left, and on unloading on the rigth

conditions. The case of non-proportional is "loosely" also more apt to ratchetting, given the proportional loading seems to fix the contact area.

\section{ALMOST CONFORMING CONTACT PROBLEMS}

In the case the problem is 'almost conforming' ie that there is an initial gap between the bodies throughout the potential contact region, or interference, the stress and displacement fields depend only on the inhomogeneous terms $g_{0}, \mathbf{U}, \mathbf{T}$ and this dependence can be expressed symbolically in the equation

$$
\mathbf{u}=\mathcal{F}\left(g_{0}, \mathbf{U}, \mathbf{T}\right),
$$

where the function $\mathcal{F}\left(g_{0}, \mathbf{U}, \mathbf{T}\right)$ includes information about the extent of the contact region. Consider now the field $\widetilde{\mathbf{u}}=\lambda \mathcal{F}\left(g_{0}, \mathbf{U}, \mathbf{T}\right)$, where $\lambda$ is a positive scalar multiplier. It is clear that this field satisfies all the homogeneous equations and inequalities in the problem and it will also satisfy the inhomogeneous conditions corresponding to a gap function $\lambda g_{0}$ and loading $\lambda \mathbf{U}, \lambda \mathbf{T}$. It follows that

$$
\lambda \mathcal{F}\left(g_{0}, \mathbf{U}, \mathbf{T}\right)=\mathcal{F}\left(\lambda g_{0}, \lambda \mathbf{U}, \lambda \mathbf{T}\right) .
$$

This result is true for all $g_{0}, \mathbf{U}, \mathbf{T}$ and hence we can replace $g_{0}$ by $g_{0} / \lambda$, to obtain $\mathcal{F}\left(g_{0}, \lambda \mathbf{U}, \lambda \mathbf{T}\right)=\lambda \mathcal{F}\left(\frac{g_{0}}{\lambda}, \mathbf{U}, \mathbf{T}\right)$.If the loading parameter $\lambda$ is increased without limit, we therefore have

$$
\lim _{\lambda \rightarrow \infty} \frac{\mathcal{F}\left(g_{0}, \lambda \mathbf{U}, \lambda \mathbf{T}\right)}{\lambda}=\mathcal{F}(0, \mathbf{U}, \mathbf{T})
$$

In other words, at sufficiently large loads, the form of the solution, including the extent of the contact area, tends to that of the corresponding conforming contact problem, regardless of whether $g_{0}$ is positive or negative. However, while this problem defined univoquely the behaviour of the conforming contact system under load $\lambda \mathbf{U}, \lambda \mathbf{T}$, the almost conforming at certain lower $\lambda$ may change behaviour. But, again, the similarity and dimensional analysis turns useful, since we don't need, for example, to study different gaps or interferences but only to study the effect of $\lambda$. In other words, while the case of conforming contact is completely independent on $\lambda$, here we need to study the further dependence on low $\lambda$, but 
there is no need to change geometry, except for the need to study one generic case of gap and one of interference.

In fact, if we 'normalize' the gap function $\hat{g}_{0}$, such that $\hat{g}_{0}=\frac{g_{0}}{L}$, where $\hat{g}_{0}$ is a dimensionless function describing the shape of the gap and $L$ is a positive scalar multiplier with dimensions of length (being $\Delta R$ in the cylindrical geometry). Substituting this in (17) and setting $\lambda=1 / L$, we obtain

$$
\mathcal{F}\left(g_{0}, \mathbf{U}, \mathbf{T}\right)=L \mathcal{F}\left(\hat{g}_{0}, \frac{\mathbf{U}}{L}, \frac{\mathbf{T}}{L}\right) .
$$

The function $\mathcal{F}$ defines the form of the displacement and stress fields and hence the extent of the contact area, which therefore depends only on the load factors $\frac{\mathbf{U}}{L}, \frac{\mathbf{T}}{L}$. Hence, starting from the conforming contact which is the limit at high $\lambda$ in any case, reducing the loads by a scalar $\lambda$ is equivalent to increasing the size $L$ which means increasing the gap. In the limit of large gap, the solution will perhaps belong to the class of self-similar profiles which we deal with in the next paragraph, and a comparison between the two limit behaviour will immediately show if there is a transition to be expected at intermediate $\lambda$. However, clearly there is no need, for example in a FEM study where changing the gap may require complete geometry redefinition, to do so, and one should study the system only with effectively one independent parameter.

For a special case of the pin-in-hole problem, the initial gap is uniform around the circumference, so we can take $\hat{g}_{0}=1$ for progressive contact. We then have $L=\Delta R$, showing that the contact semi-arc depends on the dimensionless ratio $\Phi=F /(E \Delta R)$ for two dimensional problems, where the load $F$ is here defined as an applied force per unit thickness, or need to introduce a length $W$ characterizing the dimension of the components, defining $\Phi=F /(E W \Delta R)$, where $F$ now has the dimensions of force, for three dimensional problems.

These definitions permit generalization to classes of geometrically similar systems of various materials, assuming that Poisson's ratio is the same for all. In problems where the loading is characterized by an imposed displacement $U$, the appropriate loading parameter is $\Phi=U / L$ for both two and three dimensional problems.

In terms of Bree diagram, this means that the outer region of the diagram is independent on the initial gap, and the inner region only is. The inner region therefore does not need to be sector shaped, and deviations from this shape can occur, which are however only a function of $\lambda$. Moreover, notice that conditions to have a "permanent contact area" and hence a "permanent stick area" are easier with interference, so that chance to develop residual stresses will be higher in the Bree diagram near the centre. We expect therefore the region of elastic shakedown to enlarge towards the origin.

\section{CONCLUSIONS}

We have shown that for a system loaded by a given set of forces varying in time (not necessarily cyclic) and defined in terms of a multiplicative factor $\lambda$ we prove that:

(1) In cases of completely conforming contact, the boundary conditions are homogeneous, and so the evolution of the contact areas in time will be independent on $\lambda$ regardless on how many length scales there are in the problem, like for example in a system of many 
different layers, inclusions, etc. In particular, we infer for the classical Melan problem of shakedown, that if there is possible shakedown, cyclic slip or ratchetting for a given $\lambda$ (or possibly an overlapping combination of them), then the same state will be also possible for all $\lambda$ (and there is also proportionality to $\lambda$ for cyclic slip and ratchetting rates): there are no shakedown limits in the classical sense, and it is improper to talk of lower and upper bounds. As a corollary, applying the necessary part of Melan, if there is no safe distribution of residual displacements for a given $\lambda$, then the system will not shakedown for any $\lambda$. This is very likely for example for cases when the contact area changes considerably during the cycle, as in this case there is no possibility for the system to store frictional residual displacements.

(2) A Bree-Haigh interaction diagram can be devised and for conforming contacts, this will have an open and sector shape: however, because of the dependence on initial conditions in general, multiple steady states are possible in each region, and hence perhaps worst scenario solutions need to be found, which then could scale with $\lambda$. The Bree diagram therefore will not in general have the same meaning as in plasticity.

(3) In case there is a small initial gap or interference throughout the potential contact area, we have an additional length scale (the initial clearance or interference) which means that the contact area now depends on $\lambda$. However, we can still say that the problem approaches the case with no gap for $\lambda$ tending to infinity. More in general, increasing $\lambda$ corresponds to reducing the initial gap, so that results for a variety of initial geometries (due to tolerance variations) can be obtained from a set of results for a single case with arbitrary gap.

(4) If the conforming contact limit has a precise response, involving for example, shakedown or cyclic slip or ratchetting: increasing the gap (reducing $\lambda$ ) may change this, so the limit at large gap is that of zero $\lambda$. This for example suggests a way to reduce damaging effects of friction instead of reducing the loads (however, the stress concentrations will increase).

(5) A special case is proportional loading, for which the original Dundurs' properties of receding contact continue to hold only in the first loading cycle, and otherwise the problem remains fully non-linear in subsequent cycles. There will be generally tendency to reduce energy dissipation in cases with load which has positive minimum value, where we can have a permanent contact area, and an included permanent stick area.

(6) In general, due to contact problems requiring zero pressure at the edges, the complete elastic shakedown condition is very unlikely. It can occur only in blocks systems, where we neglect the continuum description (like Coulomb 1776), or for extremely special cases where the local shear tractions are kept proportional to the pressure in a ratio lower than friction.

\section{ACKNOWLEDGEMENTS}

The author wishes to thank LMS-Ecole Polytechnique (Palaiseaux, Paris France) for invitation to spend a wonderful and very productive sabbatical year there in 2008 . Also, Proff. Salencon, Bui, Ponter, Michalowski, Barber, for useful comments. 


\section{REFERENCES}

[1] Adams G. G., Self-excited oscillations of two elastic half-spaces sliding with a constant coefficient of friction, ASME J. Appl. Mech. 62 (1995) 867-872.

[2] Ahn YJ, Barber J.R., Response of frictional receding contact problems to cyclic loading, submitted, 2008.

[3] Andersson, Lars-Erik., Quasistatic frictional contact problems with nitely many degrees of freedom, Technical Report LiTH-MAT-R-1999-22, Department of Mathematics, University of Linkoping, SE-581 83 Linkoping Sweden, 1999.

[4] Andersson, Lars-Erik and Klarbring, Anders, A review of the theory of static and quasistatic frictional contact problems in elasticity, R. Soc. Lond. Philos. Trans. Ser. A Math.Phys. Eng. Sci. 359 (2001) (1789) 2519-2539.

[5] Andersson, Lars-Erik, Quasistatic frictional contact problems. Relations between the wedge problem and the rate problem, private communication, 2008

[6] H. Anscombe and K. L. Johnson, Slip of a thin solid tyre press-fitted on a wheel, International Journal of Mechanical Sciences 16 (1974) 329-334

[7] Antoni, N., Nguyen, Q-S., Ligier, J-L., Saffré P. \& Pastor, J., On the cumulative microslip phenomenon, Eur.J.Mech. A/Solids 26 (2007) 611-625.

[8] Barber J.R., and Hild, P. , 2006. On wedged configurations with Coulomb friction, in Peter Wriggers and Udo Nackenhorst, eds., Analysis and Simulation of Contact Problems, SpringerVerlag, Berlin, pp. 205-213.

[9] Ben-Zion, Y., (2001) Dynamic ruptures in recent models of earthquake faults, Journal of the Mechanics and Physics of Solids 49 (2001) 2209-2244

[10] M Boulbibane, IF Collins, ARS Ponter, D Weichert, Shakedown of unbound pavements : Shakedown theory, Road materials and pavement design 6 (2005) (1) 81-96

[11] D Bruton, M Carr, Michael Crawford, Edgard Poiate, The Safe Design of Hot On-Bottom Pipelines with Lateral Buckling using the Design Guideline Developed by the SAFEBUCK Joint Industry Project. Deep Offshore Technology Conference Vitoria, Espirito Santo, Brazil 2005, http://www.safebuck.com/ DOT2005-SAFEBUCK_JIP-Overview.pdf

[12] Alberto Carpinteri and Claudio Scavia, Energy dissipation due to frictional shake-down on a closed crack, subjected to shear, Meccanica 28 (1993) (4) 347-352

[13] M. Carr, F. Sinclair, and D. Bruton, 2006a, Pipeline Walking - Understanding the Field Layout Challenges, and Analytical Solutions Developed for the SAFEBUCK JIP , OTC 179452006 Offshore Technology Conference Houston, Texas, U.S.A., 1-4 May 2006.

[14] M. Carr, D. Bruton, and F. Sinclair, 2006b, Lateral buckling and pipeline walking, a challenge for hot pipelines, Offshore Pipeline Technology conference, http://www.boreasconsultants.com/pdf/papers/bor_paper_005u.pdf

[15] F-K. Chang, M. Comninou and J.R. Barber, Slip between a layer and a substrate caused by a normal force moving steadily over the surface, Int. J. Mech. Sci. 25 (1983) 803-809.

[16] Hanbum Cho and J.R.Barber, Dynamic behavior and stability of simple frictional systems, Mathematical and Computer Modeling 28 (1998) 37-53.

[17] Hanbum Cho and J.R.Barber, Stability of the three-dimensional Coulomb friction law, Proc. Roy. Soc. 455 A (1999) 839-861.

[18] Churchman, C.M., Korsunsky A.M. and Hills, D.A., 2006. The application of plasticity principles to friction, J.Strain Analysis, Vol.41, pp.323-328.

[19] Ciavarella, M. Baldini, A. Barber,J.R. and Strozzi, A. , Reduced dependence on loading parameters in almost conforming contacts, International Journal of Mechanical Sciences $\mathbf{4 8}$ (2006) (9) 917-925 
[20] Ryan T. Cole and Kyle M. Rollins, Passive Earth Pressure Mobilization during Cyclic Loading J. Geotech. and Geoenvir. Engrg., Volume 132, Issue 9, pp. 1154-1164 (September 2006)

[21] Coulomb, C.A. 1776. Essai sur une application des règles des maximis et minimis à quelques problèmes de statique relatifs à l'architecture (An attempt to apply the rules of maxima and minima to several problems of stability related to architecture). Memoires de l'Academie Royale des Sciences, Paris, 7: 343-382.

[22] Dini D, Hills DA. Unsymmetrical shear loading and its in uence on the frictional shakedown of incomplete contacts, Proceedings of the Institution of Mechanical Engineers Part C: Journal of Mechanical Engineering Science, 2004, 218:469-475.

[23] Dowson D., History of Tribology, Wiley, New York, 2 edition, 1998.

[24] Drucker, D.C., Coulomb friction, plasticity, and limit loads, ASME J.Appl.Mech. 21 (1954) $71-74$.

[25] Drucker, D.C., In: Lee, E.H., Symonds, P. (Eds.), Plasticity, Pergamon Press, Oxford, pp. 407-455, 1960.

[26] Dundurs J, Stippes M., Role of elastic constants in certain contact problems, ASME Journal of Applied Mechanics 37 (1970) 965-970.

[27] Dundurs J., 1975. Properties of elastic bodies in contact in The Mechanics of the Contact between Deformable Bodies (A.D. de Pater and J.J.Kalker ed.), Delft University Press. pp.5466 .

[28] Dunham, E. M., Dissipative interface waves and the transient response of a three dimensional sliding interface with Coulomb friction, Journal of Mechanics and Physics of Solids 53 (2005) 327-357.

[29] Fichera G. , Boundary value problems of elasticity with unilateral constraints, Handbuch der Physik VI a/2, Berlin: Springer; pp.391-424, 1972.

[30] Halphen, B., 1979. Steady cycles and shakedown in elastic-viscoplastic and plastic structures. In: Mat eriaux et Structures Sous Chargement Cyclique, Association Amicale des Ingenieurs Anciens El eves de E.N.P.C., Paris, pp. 203-230.

[31] Halphen, B., Nguyen, Q.S., 1975. Sur les materiaux standard generalisees. J. Mec. 14, 39-63.

[32] Johnson KL, Contact Mechanics, Cambridge University Press, Cambridge, 1985.

[33] Klarbring A., Examples of non-uniqueness and non-existence of solutions to quasi-static contact problems with friction, Ingenieur-Archiv 60 (1990) 529-541.

[34] Krahn J., The 2001 R.M. Hardy Lecture: The limits of limit equilibrium analyses, Canadian Geotechnical Journal 40 (2003) (3) 643-660(18).

[35] Maier, G., Shakedown theory in perfect elastoplasticity with associated and nonassociated flow-laws: a finite element, linear programming approach, Meccanica, 4 (1969) 250-260.

[36] Maier G., On Some Issues in Shakedown Analysis, Journal of Applied Mechanics 68 (2001) (5) $799-808$

[37] Melan, E. Theorie statisch unbestimmter Systeme aus ideal-plastichem Baustoff, Sitzungsber. d. Akad. d. Wiss., Wien, 2A (1936) (145) 195-218.

[38] Nguyen Q-S. , On shakedown analysis in hardening plasticity, Journal of the Mechanics and Physics of Solids 51 (2003) (1) 101-125

[39] Polizzotto, C., 1993a. A study on plastic shakedown of structures, Part I: Basic properties, Part II: Theorems. J. Appl. Mech. ASME 60, 318-323, 324-330.

[40] Polizzotto, C., 1993b. The assessment of residual post-transient stresses in elastic-perfectly plastic solids subjected to cyclic loads. Rend. Mat. Acc. Lincei, s. 9 4, 133-144.

[41] Polizzotto, C., On the conditions to prevent plastic shakedown of structures, Part I: Theory, Part II: The plastic shakedown limit load, J. Appl. Mech. ASME 60 (1993c) 15-19, 20-25. 
[42] Polizzotto C., Steady states and sensitivity analysis in elastic-plastic structures subjected to cyclic loads, Int. J. Solids Struct. 31 (1994a) 953-970.

[43] Polizzotto, C., On elastic-plastic structures under cyclic loads, Eur. J. Mech. A/Solids 13 (1994b) 149-173.

[44] Polizzotto, C., Variational methods for the steady state response of elastic-plastic solids subjected to cyclic loads, International Journal of Solids and Structures 40 (2003) 2673-2697.

[45] J Salencon, de L'Elasto-plasticité au calcul à la rupture, Editions de L'Ecole Polytechnique, 91128 Palaiseau Cedex, 2002.

Received June 30, 2009

\section{THÍCH NGHI VÀ TĂNG GIẢM GẤP KHÚC TRONG HÊ̂ MA SÁT TUÂN THỦ}

Bài toán tiếp xúc có thể gặp trong nhiều lĩnh vực quan trọng: vật liệu có vết nứt, chất độn, kết cấu có lớp, hình học liên kết v.v. Ma sát Coulomb không thích ứng, có nghĩa nó không thỏa mãn định đề DruckerÒs về ổn định trong lý thuyết dẻo, do vậy không thể sử dụng các định lý Melan và Koiter đối với tải trọng chu kỳ, mực dù vậy nó vẫn là điều kiện cần. Mặt khác hình nón của ma sát coloumb có sự kì dị, sự tự tương tự tuyến tính, và điều này cho một số ít kết quả chung, rất khác nhau nhưng rất đáng kể. Ví dụ, ta thấy đối với tiếp xúc tuân thủ (conforming), đồ thị tương tác Bree mở và các đoạn nhọn hơn, và vì vậy không tồn tại cận dưới và cận trên như trong bài toán dẻo, vì ở đây có sự phụ thuộc tuyến tính vào tham số tải trọng $\lambda$, chứ không có giới hạn đối với $\lambda$. Do có sự phụ thuộc vào điều kiện ban đầu nói chung, đồ thị Bree không có cùng ý nghĩa sâu xa như $\lambda$ trong bài toán dẻo, do không thể có trạng thái ổn định dừng. Tuy nhiên, với hệ số tải có thể nhân rộng các trạng thái có thể (thích nghi đàn hồi, trượt chu kỳ, tăng giảm gấp khúc (răng cưa) ratchetting), và từ đó xác định kịch bản xấu nhất. Tuy nhiên, để phát triển ứng suất dư (mà nói chung cần nhiều chu trình đặt tải dừng), tải trọng không thể trở về 0 , it nhất đối với hệ số ma sát thấp hơn giá trị cho phép khi "tách ra" "wedging" . Nói chung, trong trạng thái dừng cần có một "vùng cứng cố định".

Hầu hết các dạng tiếp xúc tuân thủ, và đặc biệt trường hợp tương tác ban đầu, mất sự phụ thuộc vào $\lambda$ chỉ khi $\lambda$ nhỏ, nhưng lại có nhiễu khả năng tăng ứng suất dư. Tuy vậy, nghiên cứu sẽ đơn giản đi nhiều khi phát triển cách tiếp cận theo đường cong chủ để nghiên cứu sự phụ thuộc vào $\lambda$. Các định lý này có thể xem xét sự mở rộng cho tải chu trình các kết quả của Dundurrs cho trường hợp tiếp xúc tuân thủ dưới tác dụng của tải đơn điệu, khi đó miền tiếp xúc không thay đổi theo thời gian và bài toán là tuyến tính (vì vậy được gọi là "tiếp xúc giảm thiểu"). Tuy vậy, ở đây bài toán vẫn hoàn toàn phi tuyến và tiếp xúc nói chung không giảm thiểu cũng không có trang thái dừng duy nhất, ngay cả trong trường hợp tải tỷ lệ. Tuy nhiên, trong trường hợp cuối cùng có thể đưa ra một số kết quả. Từ khóa: Thích nghi, tiếp xúc giảm thiểu, tiếp xúc tuân thủ, liên kết khớp, cho phép. 